\title{
Dual Band Planar Inverted F Antenna (PIFA) with L-Shape Configuration
}

\author{
Mohamad khlouf Munzer Saidatul Norlyana Azemi, Azremi Abdullah Al-Hadi, Ping Jack Soh, Mohd Faizal Jamlos \\ Advanced Communication Engineering Centre (ACE) CoE, School of Computer and Communication Engineering, \\ Universiti Malaysia Perlis (UniMAP), Pauh Putra, Arau 02600, Malaysia.
}

\begin{abstract}
One of the most used antennas in mobile devices is planar inverted $\mathrm{F}$ antenna (PIFA). PIFA can be design in dual band frequencies due to the coverage of the wireless service in a mobile device that requires a multiple frequencies. However, the consideration of technical operation has to be combined with an evaluation of the antenna radiation impact on the users. A procedure of PIFA work in GSM $(867-960 \mathrm{MHz})$ and GSM $(1710-1899 \mathrm{MHz})$ is done using CST Software. The dual band frequency response is obtained by means of an insertion of an Lshaped slot, which is use to tune the operation frequencies. The prototype of the antenna is fabricated as model by CST Software and evaluated. It is found out that the PIFA antenna has a good efficiency, bandwidth as well as produce a maximum gain for the antenna. A key and innovative research is still underway to broaden performance parameters of the antenna.
\end{abstract}

\section{Introduction}

Most common built in antenna which becomes very promising candidates for applications in mobile handsets is Planar Inverted $\mathrm{F}$ Antenna (PIFA) [1]. Planar Inverted-F antennas (PIFAs) are among the most generally utilized receiving wires in portable terminals [2]. The PIFA have some unique characteristic that makes it suitable to use in portable wireless device especially on mobile handsets. It has many advantages compared to other microstrip antennas, where it has a low profile, small size and can be located in a place such as at the back of the mobile phone [3]. On the other hand, the other major antennas are easy to fabricate, sample structure, low manufacture cost and low Specific Absorption Rate (SAR) value where it has a small backward radiation toward the used head [4].

There are two type of antenna used for mobile phone which are external and internal. At first, the use of the external antenna had been used widely with the previous generation of the mobile such as Helical Antenna mobile, however due to today's market trends the demand has been placed on reducing the handset size where the antenna must be within size and performance as required compared to the hand-phone [5-6]. The size of the mobile have been reducing in size and weight over time, where an internal antenna must be used instead of external antenna. Therefore, there have been many evolutions of antenna structure due to the decreasing in mobile size and high performance required.

Due to the new era where human depend on mobiles and the size of the phone become slimmer and the performance become higher, hence it is essential to develop an antenna that can be able to accommodate to all the requirement with maximum performance. But, antenna size is a major factor that limits device miniaturization. Hence, the objective of this project is to develop low profile and realizable antenna that is capable to operate at GSM frequency band.

\section{Antenna development}

The fundamental parameters of PIFA design are the longitude of the patch ( $L$ and $W$ ), the height of the structure $h$, the width of the shorting wall $w$, and the distance from the feeding to the wall. The dimensions of the $L, W$ and the $h$ are chosen to achieve a certain resonant frequency as follow:

$(L+h) \sqrt{ } \varepsilon_{r} \cong \lambda 4$

If the size of shorting pin is reducing, the electromagnetic waves will travel a longer distance, for which the condition of resonance is transformed into:

$(L+W+h) \sqrt{\varepsilon_{r}} \approx \lambda 4$

Several considerations obtained from diverse parametric studies will be taken to design a PIFA: the bandwidth of the PIFA increases with the $h$ (as in the case of the conventional patch antenna), and the dimension of the patch determine the resonant frequency (bigger patch, lower frequency). Also, the variations of parameters have been carried out (position of the shorting wall, position of the feeding, height of the layer of air) for tuning the structure. At the beginning, a patch that operates at GSM 900 band was designed, and the second frequency is excited with the insertion of the Lshaped slot with a length around $\lambda / 4$ for GSM 1800 band.

$f(G H z) \approx 300 /\left[4(L(m m)+W(m m)+h(m m)) \sqrt{ } \varepsilon_{e f f}\right]$

The following equation is used to obtain the upper frequency band

$f(G H z) \approx 300 /\left[4(L 2(m m)+L 3(m m)) \sqrt{ } \varepsilon_{e f f}\right]$ 


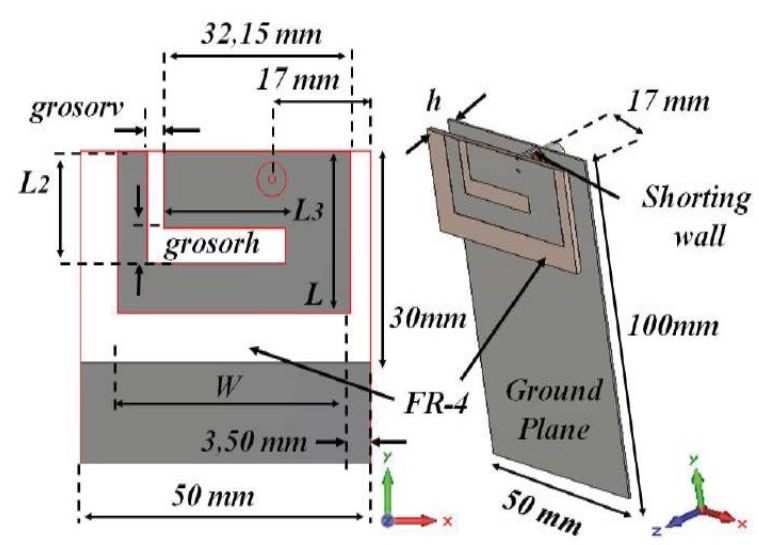

Fig. 1. Configuration of the PIFA antenna with L-shaped slot.

In order to maintain the first resonant frequency (the lower) the dimension of the patch is adjusted. The configuration of the proposed antenna is presented in Figure 1, and it can be seen that there is an air separation between the ground plane and the substrate that hold the patch. For this case an effective dielectric constant is used in the above equations

$\varepsilon_{e f f}=\varepsilon_{r} .\left(h_{s}+h_{\text {air }}\right) \varepsilon_{r} . h_{\text {air }}+\varepsilon_{\text {air }} . h_{s}$

The feeding and the shorting wall are in line in Figure 1, separated by $4 \mathrm{~mm}$ from the edge where is located the shorting wall to the centre of the coaxial probe feed.

Table 2. Parameter of PIFA antenna with L-shaped slot

\begin{tabular}{|c|c|}
\hline Parameters & Value \\
\hline$L 2$ & $16 \mathrm{~mm}$ \\
\hline$L 3$ & $21 \mathrm{~mm}$ \\
\hline$W$ & $40 \mathrm{~mm}$ \\
\hline$L$ & $23 \mathrm{~mm}$ \\
\hline $\begin{array}{l}h \text { ( height of the shorting } \\
\text { wall ) }\end{array}$ & $7.5 \mathrm{~mm}$ \\
\hline $\begin{array}{l}\text { hs ( height of the FR } \\
\text { substrate-4) }\end{array}$ & $1.58 \mathrm{~mm}$ \\
\hline $\begin{array}{l}\text { hair ( height of the } \\
\text { separation of air ) }\end{array}$ & $5.92 \mathrm{~mm}$ \\
\hline $\begin{array}{l}\text { hpt ( height of the copper } \\
\text { ground plane ) }\end{array}$ & $0.6 \mathrm{~mm}$ \\
\hline $\begin{array}{l}h c \text { ( height of the copper } \\
\text { microstrip antenna) }\end{array}$ & $0.035 \mathrm{~mm}$ \\
\hline Total height $(h p t+h+h c)$ & $8.135 \mathrm{~mm}$ \\
\hline $\begin{array}{l}\text { grosorv (width of the } \\
\text { vertical slot of the L ) }\end{array}$ & $2.7 \mathrm{~mm}$ \\
\hline $\begin{array}{l}\text { grosorh (width of the } \\
\text { horizontal slot of the L ) }\end{array}$ & $5 \mathrm{~mm}$ \\
\hline $\begin{array}{c}\text { er (dielectric constant of the } \\
\text { FR-4 substrate) }\end{array}$ & 4.3 \\
\hline $\begin{array}{c}\tan \delta \text { ( loss tangent of the } \\
\text { FR-4) }\end{array}$ & 0.025 \\
\hline width of the shorting wall & $0.6 \times 1 \mathrm{~mm}$ \\
\hline
\end{tabular}

\section{Result and Discussion}

\section{$3.1 \mathrm{~S}_{11}$ measurement Vs simulation}

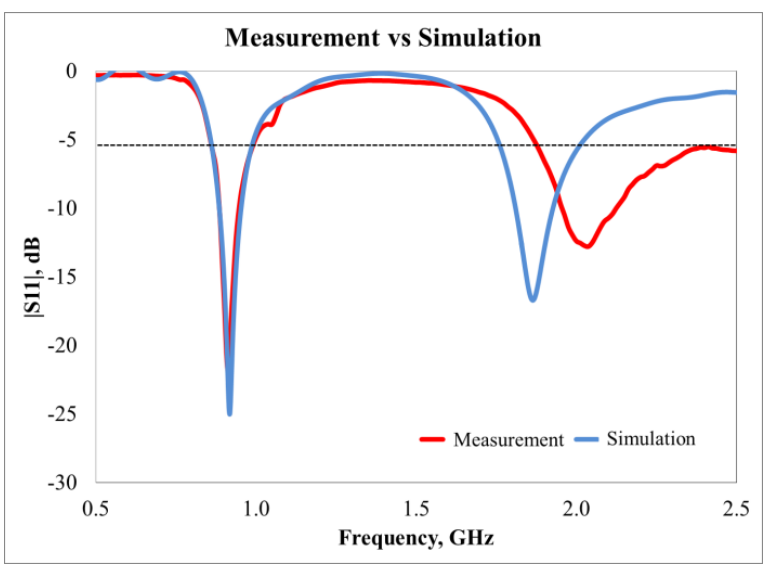

Fig. 2. $\mathrm{S}_{11}$ Measurement Vs Simulation Result

The simulation and measured result are Figure 2 where both result simulation and measurement are approximately the same. Measurement result drops at 0.9 $\mathrm{GHz}$, whilst simulation result drops at $0.9 \mathrm{GHz}$. The antenna copper wire angle of the design hardware will affect the result. These may happen because of manual fabrication and designing hardware where the angle is very difficult to make it $90^{\circ}$ which is like a sharp angle as same in simulation design. The length of copper wire of antenna played a significant role because of the curved angle not sharply $90^{\circ}$ and possibility length of copper wire is more than the simulation design. From the analysis, slightly different of the length and the curved angle antenna will affect the actual result. Nevertheless, the different is almost neglect able. Return loss value of the measured result shows that it is in good value for the radiation signal where the insertion loss value is less than -10 .

\subsection{VSWR measurement Vs simulation result.}

Shown in figure 3 is VSWR measurement versus simulation result. It is shows that, both of the results are approximately the same. VSWR is defined as the ratio of the maximum voltage to the minimum voltage in standing wave pattern along the length of a transmission line structure. It varies from 1 to (plus) infinity and is always positive. From the result, all the value is positive at the targeted frequency and it is approaching to 1.

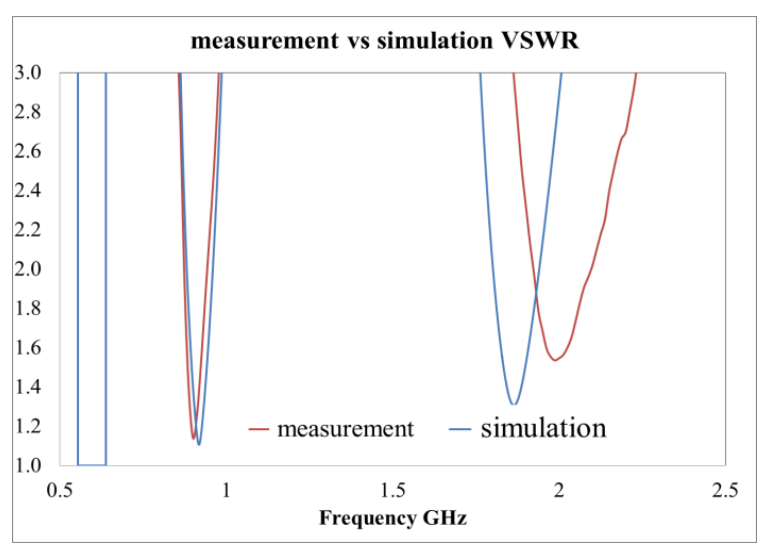

Fig. 3. VSWR Measurement Vs Simulation Result. 


\subsection{Antenna Gain}

Antenna gain is the main performance which is combined the antennas directivity and electrical efficiency. The gain of an antenna is defined as the amount of energy radiated in a particular direction compared to the amount of energy directed in the same direction of an isotropic antenna. For this PIFA antenna gain value are $1.79 \mathrm{~dB}$ at $0.9 \mathrm{GHz}$ and $4.02 \mathrm{~dB}$ at $1.9 \mathrm{GHz}$, Since the gain is sufficiently low, The low gain value will not affect the human body.
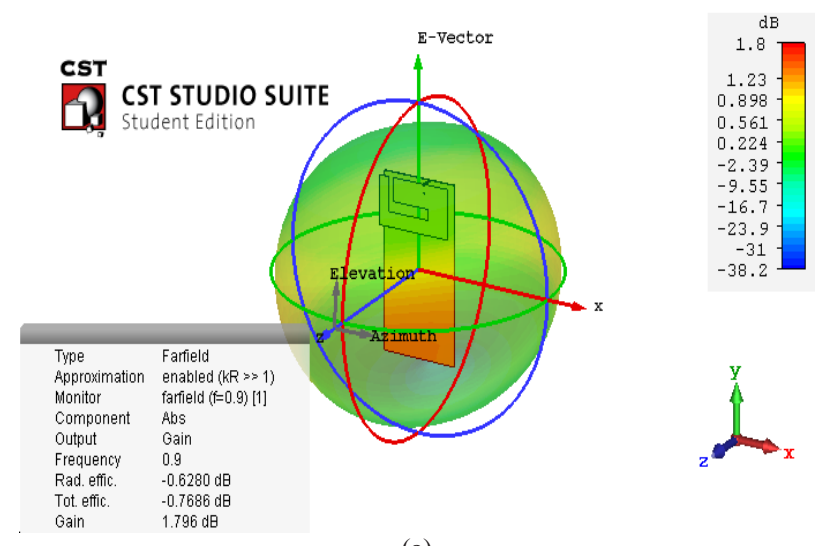

(a)

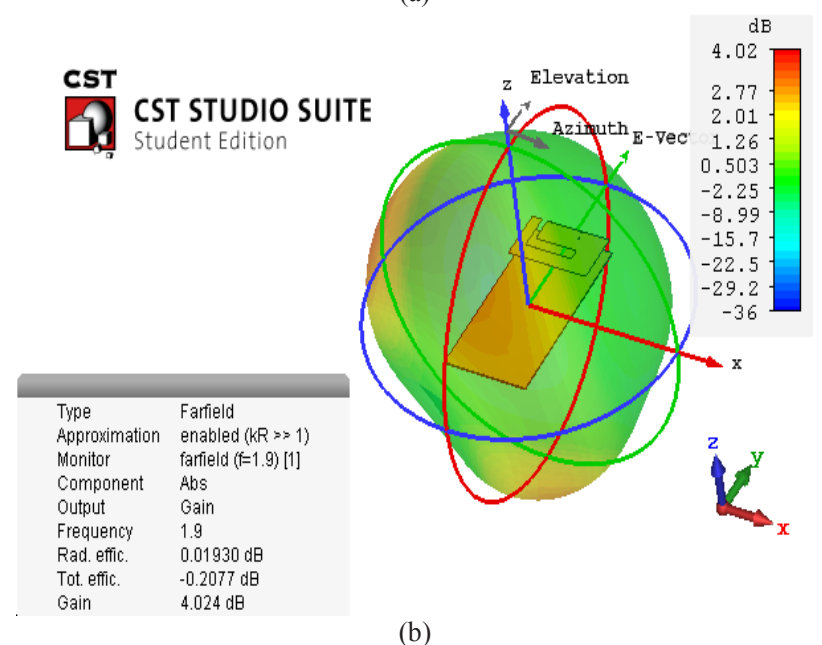

Fig. 4. PIFA Antenna Radiation Pattern a) at $0.9 \mathrm{GHz}$, b) at $1.9 \mathrm{GHz}$.

\subsection{Surface current distribution}

Figure 5 shows the parts where more current intensity flows at each frequency. For the lower frequency of $0.9 \mathrm{GHz}$, in the outer part circulates the majority of the current, meanwhile for the superior frequency of $1.9 \mathrm{GHz}$ is in the inner rectangular part. In Figure 6, it is observed the influence of the L-shaped slot in the surface current distribution, where it is more intense the current near the slot for 1.9 GHz.

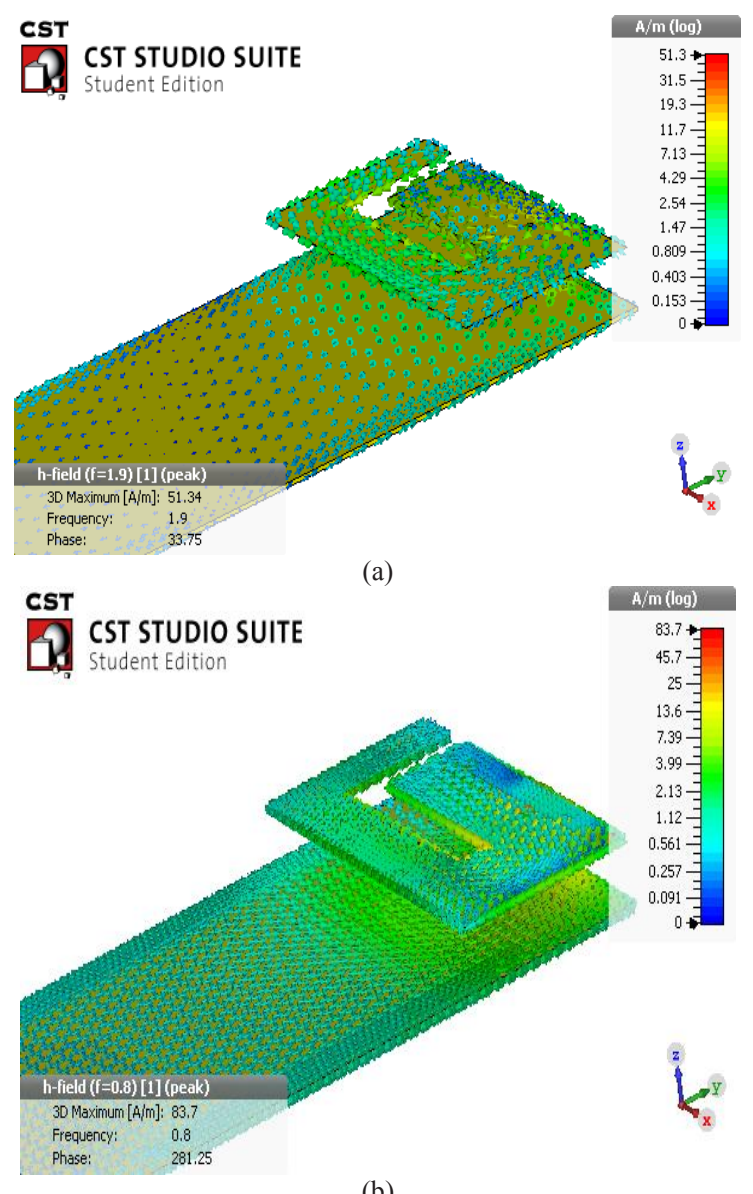

(b)

Fig.5. Surface Current Distribution In The Structure. a) at $1.9 \mathrm{GHz}, \mathrm{b}$ ) at $0.8 \mathrm{GHz}$.

\subsection{Antenna Efficiency}

Efficiency is measured by integrating the total power flux or gain measured over the whole spherical surface. It is measure the radio antenna which is converts the radio frequency power into radiated power. Efficiency is the ratio of power actually radiated to the power put into the antenna terminals. The good percentage efficiency of antenna is must be more than $90 \%$ for the better radiation of antenna. This PIFA antenna was in good efficiency with the percentage of efficiency around $90 \%$ as shown in Figure 6.

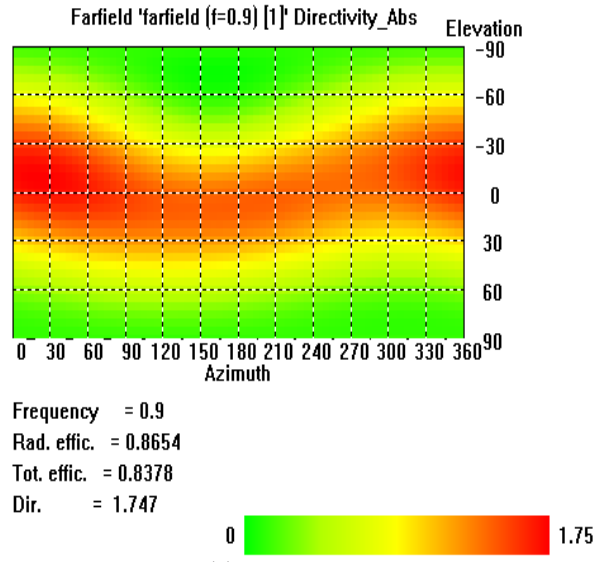

(a) 


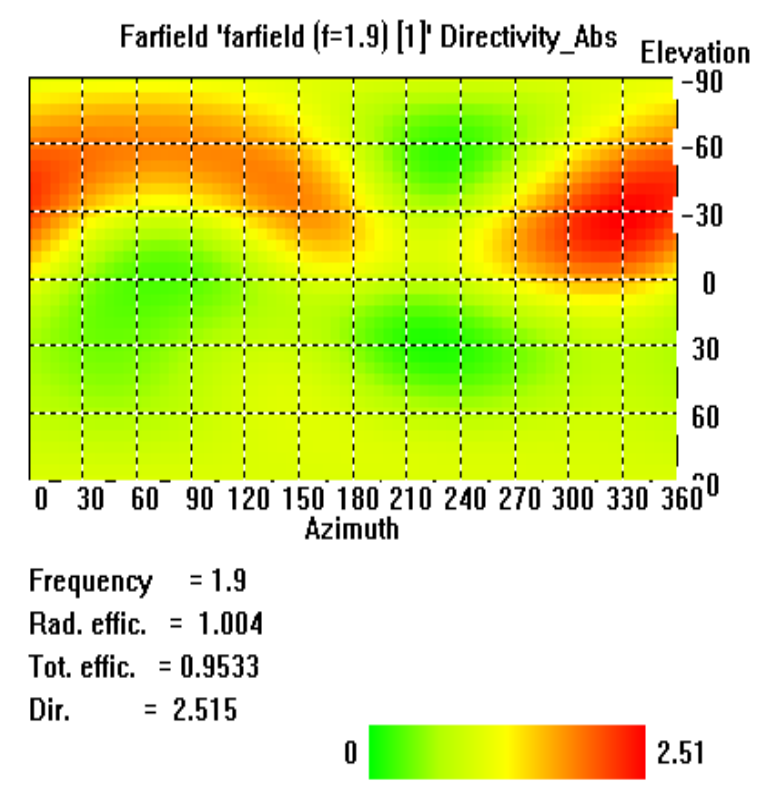

(b)

Fig. 6. PIFA antenna efficiency. (a) at $0.9 \mathrm{GHz}$, (b) at $1.9 \mathrm{GHz}$

\section{Conclusion}

This research is to develop a PIFA antenna that covers the frequency range for mobile phone applications. The antenna is a modification of traditional design of PIFA by creating an L-slot that covers GSM $(876-960 \mathrm{MHz})$ and (1710-1889 MHz) frequency band. The antenna was tested for suitability in mobile telephony applications, analysis of radiation patterns were made and gain and efficiency. It was observed that the radiation patterns were omnidirectional in the two planes and thus makes the antenna very suitable for mobile phone applications. Vertical and horizontal polarization effects were analysed due to the need of the phone working correctly regardless of the antenna's orientation. The radiation patterns indicated a high front to back ratio, this could point to the fact that the antenna produces a low Specific Absorption Rate value.

\section{References}

1. P. Lindberg, "Wideband active and passive antenna solutions for handheld terminals", Uppsala University, 2007.

2. N. Misran, M. M. Yunus and M.T. Islam, " Small Dual-Band Planar Antenna with Folded Patch Feed", Journal of Applied Sciences Research, 6(12), 2010.

3. K. QuLuhaibboa, S. Luhaib and B. Abaoy, "Design and Simulation Dual-Band PIFA Antenna for GSM Systems", International Multi-Conference on Systems, Sygnals \& Devices, pp. 1-4, 2012.

4. D. G. Kang and Y. Sung, "Compact hexabandpifa antenna for mobile handset applications," Antennas and Wireless Propagation Letters, IEEE, vol. 9, pp. 1127-1130, 2010.

5. Y. Nie and L. Song, "A Compact Triband Fractal PIFA Antenna for Mobile Handset Applications", 2013.

6. J. Chen, L. Ying and Y. Ban, "Compact PIFA using capacitive coupled-fed for LTE/GSM/UMTS WWAN operation in the mobile application", vol. 1, pp. $414-417,2011$. 